\title{
FALTA DE LEGITIMACIÓN ACTIVA EN IMPUGNACIÓN DE FILIACIÓN NO MATRIMONIAL: COMENTARIO A LA SENTENCIA 288/2020 DE LA AUDIENCIA PROVINCIAL DE BARCELONA, DE 25 DE MAYO DE 2020*
}

\author{
LACK OF ACTIVE LEGITIMACY IN CONTESTING \\ NON-MARRIAGE FILIATION: COMMENTS ON JUDGMENT \\ 288/2020 OF THE BARCELONA PROVINCIAL COURT, \\ ISSUED ON MAY 25, 2020
}

\author{
Silvia VILAR GonZÁlEZ** \\ Profesora Universitat Jaume I. Castellón de la Plana \\ Profesora Universidad Internacional de La Rioja \\ Oficial de Notaría
}

Recibido: 19.11.2020 / Aceptado: 04.12.2020

DOI: https://doi.org/10.20318/cdt.2021.6022

\begin{abstract}
Resumen: Esta sentencia aborda un recurso de apelación interpuesto contra una resolución dictada en un proceso de impugnación de filiación no matrimonial con respecto del padre de un menor. El procedimiento fue iniciado por la tía del niño que ejercía su guarda de facto en virtud de una irregular delegación de responsabilidades parentales efectuada por los progenitores del menor. En la sentencia, como veremos, la Audiencia Provincial además de determinar que la actora no ostentaba legitimación activa para instar el procedimiento, apreció la falta de jurisdicción internacional de los tribunales españoles para conocer de la acción ejercitada, así como una situación irregular y riesgo notorio en la situación jurídica del menor cuya filiación se debate, lo que precisaba de la adopción de las medidas oportunas.

Palabras clave: impugnación de la filiación, filiación no matrimonial, falta de legitimación activa, falta de competencia jurisdiccional, forum conveniens.
\end{abstract}

\begin{abstract}
This judgment addresses an appeal filed against a decision issued in a process to contest non-marriage filiation with respect to the father of a minor. Said procedure was initiated by the aunt of the child who exercised de facto guardianship by virtue of an irregular delegation of parental responsibilities carried out by the minor's parents. In the judgment, as we will see, the Provincial Court, in addition to determining that the plaintiff did not have active legitimacy to initiate the procedure, appreciated the lack of international jurisdiction of the Spanish courts to hear the action brought, as well as an irregular situation and notorious risk in the legal situation of the minor whose parentage is debated, which required the adoption of the appropriate measures.
\end{abstract}

Keywords: contesting filiation, non-marriage filiation, lack of active legitimacy, lack of jurisdiction, forum conveniens.

Sumario: I. Introducción. II. Antecedentes de hecho. III. Fundamentos jurídicos apreciados por la Audiencia Provincial de Barcelona. IV. Fallo. V. Consideraciones finales.

\footnotetext{
*SAP Barcelona (Sección no. 12) nº 288/2020, 25 mayo 2020 (ECLI: ES:APB:2020:3698).

${ }^{* *}$ Miembro del Grupo de Investigación "Centro de Estudios de Derecho y Relaciones Internacionales (CEDRI)".
} 


\section{Introducción}

1. Como todos sabemos, en los procedimientos de filiación concurre un componente especialmente sensible cuando el sujeto con respecto a quien se dirige la reclamación o la impugnación de dicha circunstancia es un menor de edad, al tratarse estos de personas vulnerables que precisan de una protección más reforzada.

2. La innegable confluencia de intereses públicos y privados en la labor de protección de los niños suele hacer necesario que, junto con la resolución del caso en estos supuestos, sea procedente valorar la necesidad de adoptar las medidas de protección específicas en caso de que se aprecie la existencia de un riesgo notorio en la situación jurídica del menor.

3. Cabe señalar también que, en algunos supuestos como el presente, se aprecian graves irregularidades con respecto al ejercicio de la patria potestad por parte los progenitores, en especial, en aquellos casos en que se delega la guarda y custodia del menor a favor de terceras personas, lo que permitirá a estas hacerse con el control del niño, como veremos.

\section{Antecedentes de Hecho}

4. Pues bien, en el mencionado contexto y por lo que respecta al caso que nos ocupa, en el año 2014 un niño llamado "Máximo" nació en la República de Argentina. Su nacimiento se inscribió en el Registro del Estado Civil y Capacidad de las Personas argentino correspondiente a la ciudad de residencia de ambos progenitores, que son "Amalia", su madre biológica, y "Guillermo" quien, pese a no ser el padre biológico del menor, reconoció la paternidad del niño.

5. En el año 2015 y tan solo doce días tras el nacimiento del menor, su madre biológica se lo entregó a "Tania", tía paterna del niño, y los dos progenitores del mismo (padre y madre) llevaron a cabo una delegación de las responsabilidades parentales ante un notario a favor de esta última.

6. Poco después, "Tania" se trasladó con "Máximo" hasta Barcelona, haciendo uso de un poder que los padres le habían conferido para poder viajar al extranjero en compañía del niño. Cabe destacar que "Máximo" ha venido residiendo en Barcelona con su tía desde dicho momento, teniendo establecida en este lugar su esfera de relaciones personales, incluida su escolarización.

7. En el año 2016, "Tania" interpuso una demanda de impugnación de la filiación paterna del niño alegando que la inscripción de su paternidad en el Registro Civil argentino se había efectuado en fraude de ley lo que, según la sentencia, carece de cualquier refrendo probatorio y se sostiene, únicamente, en las manifestaciones de la parte actora. A estos efectos, la hermana del demandado afirmó que "por un acto caritativo al ver que el niño no tendría padre reconocido, y viendo a la madre biológica -que era amiga suya- desvalida, convenció a su hermano para que falsamente reconociera la paternidad del niño" . De todo ello se desprendería, además, que quién urdió el fraude de ley en el que se fundamentaría la acción ejercitada, fue precisamente la tía paterna.

8. Cabe señalar que la acción se interpuso ante los órganos jurisdiccionales españoles pese a que, en el momento de interponer la demanda, tanto el padre como la madre del niño, tenían su domicilio y residencia habitual en Argentina, lugar en el que asimismo se inscribió el nacimiento del menor, tal y como hemos señalado con anterioridad. Asimismo, cabe señalar que en el procedimiento también intervino el Ministerio Fiscal y que fue llamada en calidad de demandada la madre del niño, "Amalia", quien no se opuso a la apelación, ni compareció ante el Tribunal.

${ }^{1}$ Tercer párrafo del fundamento de derecho Tercero de la SAP Barcelona 288/2020. 
9. Resulta necesario apuntar también que la sentencia del órgano jurisdiccional de instancia objeto de recurso, estimó la demanda interpuesta respecto de la impugnación de la filiación no matrimonial del menor, declarando que el niño no era hijo biológico de "Guillermo" y, por ello, acordó modificar los apellidos del niño.

\section{Fundamentos jurídicos apreciados por la Audiencia Provincial de Barcelona}

10. Ante la referida sentencia estimatoria, el demandado interpuso un recurso de apelación que se articulaba, fundamentalmente, en torno a cuatro argumentos jurídicos:

a) una falta de motivación en la sentencia, en la medida en que no se pronunciaba en torno al fraude de ley alegado en la contestación a la demanda;

b) en segundo lugar y de forma subsidiaria, por no haber sido apreciada la falta de legitimación activa de la demandante;

c) ante una falta de litis consorcio pasivo necesario, y;

d) ante una indebida interpretación del artículo 767.4 de la Ley de Enjuiciamiento Civil, el cual dispone expresamente que una negativa injustificada a someterse a la prueba biológica de paternidad o maternidad, facultará al órgano jurisdiccional para declarar la filiación que estuviera reclamándose, "siempre que existan otros indicios de la paternidad o maternidad y la prueba de ésta no se haya obtenido por otros medios"2.

11. La Audiencia Provincial de Barcelona, antes de entrar a valorar los referidos argumentos, comprobó la vinculación jurisdiccional que determinaba la competencia de la jurisdicción española para el conocimiento del proceso y también la ley aplicable al fondo del asunto, por considerar a ambos como cuestiones de orden público.

12. Con respecto al anclaje competencial, el Tribunal determinó que la acción impugnatoria de la filiación hubiese correspondido ser enjuiciada por los juzgados en los que radica el Registro argentino en el que fue inscrito el nacimiento del menor -por haber nacido en dicho lugar- y en el que tenían establecido su domicilio y residencia los progenitores del niño. Todo ello en base a lo dispuesto en el artículo 22.1 de la Ley Orgánica del Poder Judicial y al principio de reciprocidad, al atribuir dicho artículo "la competencia territorial al lugar en que se encuentra el registro en el que figura la inscripción"3. Según señala la sentencia, también el artículo 581 del Código Civil de la República Argentina -vigente en el momento del nacimiento del menor- atribuía la competencia jurisdiccional a los órganos del lugar en que se practicó la inscripción del nacimiento o bien, de forma alternativa, a los del lugar en que se halle el domicilio del demandado, es decir, el padre del menor cuya paternidad se impugna, lo que nos conduce, en ambos casos, a los tribunales argentinos.

13. Por lo tanto, procedería considerar que el foro español elegido para llevar a cabo la acción de impugnación de la filiación, "por ser el de la residencia circunstancial del niño donde ha fijado la residencia su tía", es un "forum conveniens" que podría llegar a entrañar un fraude procesal en la elección, tal y como señala el recurrente.

\footnotetext{
${ }^{2}$ Art. 767.4 LEC, in fine.

${ }^{3}$ Cuarto párrafo del Fundamento de Derecho segundo de la SAP Barcelona 288/2020.

${ }^{4}$ Cabe señalar que el Código Civil y Comercial de la Nación es el actualmente vigente en Argentina -en concreto desde el día 1 de agosto de 2015-, habiendo sido promulgado el 7 de octubre de 2014.

${ }^{5}$ Cuarto párrafo del Fundamento de Derecho segundo de la SAP Barcelona 288/2020.

${ }^{6}$ Recordemos, a estos efectos, que la doctrina del "forum conveniens" -o, más bien, del "fórum non conveniens"-, muy frecuente en los sistemas de common law, permitiría que el tribunal legalmente competente pudiera abstenerse en el ejercicio de su jurisdicción y declinar conocer del asunto en aquellos casos en que aprecie la existencia de "una jurisdicción más apropiada o en mejores condiciones para resolver el caso que él mismo, al que apunta la norma de competencia”. B. SÁNCHEZ LópEZ,
} 
14. Pese a ello, al subsistir la duda sobre si debe considerarse que el domicilio del menor radica en Barcelona, al llevar residiendo en este lugar desde el año 2015 y tener establecida en esta ciudad su esfera de relaciones personales, cabe otorgarle protección conforme a lo dispuesto en el artículo 5.1 del Convenio de la Haya de 19 de octubre de 1996, relativo a la competencia, la ley aplicable, el reconocimiento, la ejecución y la cooperación en materia de responsabilidad parental y de medidas de protección de los niños, el cual atribuye expresamente competencia a "[1]as autoridades, tanto judiciales como administrativas, del Estado contratante de la residencia habitual del niño [...] para adoptar las medidas para la protección de su persona o de sus bienes" (art. 5.1 Convenio de la Haya).

15. En cuanto al derecho aplicable, la sentencia identifica con una cuestión de orden público considerar "que la legislación aplicable a la filiación es la de la nacionalidad del menor, que también es la del lugar de su nacimiento y la de sus progenitores, además del lugar de residencia de los mismos"”, y no la normativa catalana en materia civil que fue invocada por la demandante, en base al principio de territorialidad. Pese a ello, también deben tenerse en cuenta ciertas excepciones de aplicación a los menores con residencia en España, de conformidad con lo dispuesto en el artículo 9.4 del Código Civil.

16. En dicho sentido, en los procesos caracterizados por la vinculación de la persona cuya filiación se cuestiona con los ordenamientos jurídicos de dos o más países, no podemos tampoco olvidar el amplio debate científico y normativo que sigue existiendo en torno a los criterios de conexión que permiten concretar la determinación del ordenamiento aplicable al estatuto personal, como son la nacionalidad, el domicilio o la residencia habitual del menor ${ }^{8}$. Dicha complejidad ha tratado de ser abordada, entre otras, en las sentencias del Tribunal Supremo $223 / 2018^{9}$ y 224/2018 ${ }^{10}$, ambas de 17 de abril de 2018, las cuales han demostrado ser un claro referente "del buen hacer de tantos jueces interesados en afrontar la complejidad consustancial a las situaciones privadas de tráfico externo, que se acentúa cuando se trata de la determinación de la filiación y los mecanismos de regulación no son del todo satisfactorios" ${ }^{\prime 1}$. Así, en las referidas sentencias del Tribunal Supremo y en relación con la naturaleza de la norma de conflicto contenida en el artículo 9.4 del Código Civil, este órgano ha resuelto aplicar de la regla conflictual que viene "designada por la ley de la residencia habitual del hijo en el momento del establecimiento de la filiación" "12.

17. Entrando ya en los motivos alegados expresamente por el recurrente, la cuestión relativa al fraude de ley que la demandante afirma que afecta a la inscripción de la paternidad del niño, tal y como hemos señalado con anterioridad, los magistrados de la Audiencia Provincial de Barcelona estiman que fue precisamente la tía quien urdió el fraude y que, por tanto, tal y como se desprende de lo dispuesto en los artículos 6 y 7 del Código Civil y en el artículo 247 de la Ley de Enjuiciamiento Civil, "en base al principio jurídico universal [...] los actos y negocios jurídicos realizados en fraude de ley no pueden obtener la tutela judicial y en ningún caso se puede beneficiar de los mismos quien actuó de tal forma"'13. Es más, tal y como señala la sentencia "obiter dicta", cabe establecer la filiación a través del reconocimiento de complacencia con plenos efectos jurídicos y más, partiendo de la base en el presente supuesto de que el padre del menor reconoció la paternidad del niño y "prestó su declaración ante el juez encargado del Registro Civil con pleno conocimiento de la trascendencia de tal negocio jurídico" ${ }^{14}$,

"Responsabilidad parental y la aplicación del forum non conveniens de carácter reglado del artículo 15 del Reglamento (CE) n’. 2201/2003: La STJUE de 27 de octubre de 2016”, Cuadernos de Derecho Transnacional, vol. 10, nº. 1, marzo 2018 , p. 642.

${ }^{7}$ Sexto párrafo del Fundamento de Derecho Segundo de la SAP Barcelona 288/2020.

${ }^{8}$ A. Rodríguez Benot, "El criterio de conexión para determinar la ley personal: un renovado debate en derecho internacional privado", Cuadernos de Derecho Transnacional, vol. 2, no. 1, marzo 2010, p. 188.

${ }^{9}$ STS (Sala de lo Civil) $n^{\circ}$. 223/2018, 17 abril 2018 (ECLI: ES:TS:2018:223).

${ }^{10}$ STS (Sala de lo Civil) no. 224/2020, 17 abril 2018 (ECLI: ES:TS:2018:224).

${ }^{11}$ M. GUZMÁn ZAPATER, "La filiación internacional a examen por el Tribunal Supremo. A propósito de las sentencias TS 223 y 224 de 17 de abril de 2018", Cuadernos de Derecho Transnacional, vol. 11, n'. 2, octubre 2019, p. 625.

${ }^{12}$ M. GUZMÁn ZAPATER, "La filiación internacional a examen...", cit., p. 627.

${ }^{13}$ Tercer párrafo del Fundamento de Derecho Tercero de la SAP Barcelona 288/2020.

${ }^{14}$ Primer párrafo del Fundamento de Derecho Cuarto de la SAP Barcelona 288/2020. 
lo que deberá presumirse mientras ninguna persona que ostente legitimación activa ejercite una acción impugnatoria de tal circunstancia.

18. Por lo que respecta a la falta de legitimación activa de la demandante alegada por el recurrente y padre del menor, apunta la sentencia que tanto la legislación argentina como la catalana establecen un criterio de legitimación "ad personam" que reserva al propio menor y a sus progenitores la facultad de ejercitar una acción de filiación, siempre y cuando no les hubiera caducado tal derecho. Por tanto, se estima que la tía paterna, efectivamente, carecía de legitimación activa para iniciar el proceso, independientemente de que la madre biológica del niño compareciera con posterioridad en calidad de demandada -tras ser llamada por la tía a dichos efectos-, únicamente con la intención de allanarse a la demanda y a través de un poder notarial otorgado en Argentina, el cual carecía además de la correspondiente cláusula especial dirigida a facultar un acto de la naturaleza que se pretende.

19. Es más, como también señala la sentencia, aunque la madre del menor hubiese comparecido de forma personal adhiriéndose a la demanda, ello no habría logrado subsanar la absoluta falta de legitimación activa de la tía del niño, dado que la acción impugnatoria que hubiera podido ejercitar la madre ya se hallaba caducada en dicho momento.

20. En último lugar, la sentencia también acoge la invocación del recurrente de la falta de litisconsorcio pasivo necesario, al apreciar un conflicto de intereses entre el menor su madre biológica y su padre y "Amalia", persona que viene ejerciendo las funciones de "guarda de facto", por lo que se precisaría de la intervención en el procedimiento de un defensor judicial que tratara de asegurar el interés superior del menor, así como para tratar de "esclarecer las circunstancia en las que se produjo esa peculiar delegación general de las funciones de la responsabilidad parental a la tía paterna, y la eventual situación de riesgo jurídico del niño, que se encuentra separado de quienes constan como sus padres en el registro civil, sin que se haya constituido la institución tutelar que, con toda probabilidad, será necesario constituir" ${ }^{15}$.

21. Por último, en cuanto a la indebida interpretación del artículo 767.4 de la Ley de Enjuiciamiento Civil ${ }^{16}$, el cual permite al tribunal declarar una filiación reclamada ante una negativa injustificada a someterse a una prueba biológica de paternidad o de maternidad, consideran los magistrados de la Audiencia Provincial que no puede atribuirse ningún efecto a la prueba analítica irregular, llevada a cabo son el consentimiento del interesado y sin contar con ninguna garantía en la cadena de custodia del material orgánico objeto de análisis.

\section{Fallo}

21. Tras lo expuesto y fundamentado, la Sección número 12 de la Audiencia Provincial de Barcelona, terminó estimando el recurso de apelación interpuesto por "Guillermo", revocando la sentencia impugnada y procediendo a declarar la "falta de legitimación activa de la demandante, así como la falta de jurisdicción internacional de los tribunales españoles para conocer de la acción ejercitada" ${ }^{17}$, dejando expresamente imprejuzgada la acción de impugnación de la filiación paterna que ha sido indebidamente llevada a cabo.

22. Se instó también al Ministerio Fiscal y a la entidad pública competente en esta materia del lugar de residencia del menor, esto es, la Dirección General de Atención a la Infancia y Adolescencia de la Generalitat de Cataluña, para que instruyeran el expediente oportuno y adoptaran las medidas de

\footnotetext{
${ }^{15}$ Cuarto párrafo del Fundamento de Derecho Tercero de la SAP Barcelona 288/2020.

${ }^{16}$ Art. 767.4 LEC, in fine.

${ }^{17}$ Primer párrafo del Fallo de la SAP Barcelona 288/2020.
} 
protección necesarias ${ }^{18}$, habida cuenta de la situación irregular y del riesgo notorio en la situación jurídica del menor, quien continúa residiendo en la actualidad con su "guardadora de facto", su tía paterna, "Tania". Entre las posibles medidas a adoptar, se mencionan en la sentencia el acogimiento en familia del menor, instar la suspensión o privación a los padres biológicos de la patria potestad, en su caso, o cualquier otra que se estime oportuna.

\section{Consideraciones finales}

23. Destaca especialmente en el supuesto objeto de estudio, las irregularidades en torno a la atribución de las responsabilidades parentales y ejercicio de la guarda de facto llevada a cabo por parte de la tía del menor, que le llevaron incluso a considerarse con la legitimación suficiente como para poder interponer un procedimiento por el que se cuestionase la determinación de la paternidad del niño, alegando la comisión de fraude de ley por parte de este, cuando es a la propia demandante a quien procedería considerar instigadora del fraude, en su caso.

24. Pese a ello, hemos podido comprobar también, a partir de la sentencia, la necesidad de que este tipo de procedimientos sean iniciados por las personas normativamente legitimadas para ello, que tanto en el caso de España como de Argentina son, o bien el hijo o hija, en cualquier momento, o bien sus progenitores dentro de los plazos legalmente establecidos a dichos efectos.

25. Con la última reforma normativa del artículo 9.4 del Código Civil, en cuanto a la determinación del Derecho aplicable a este tipo de procedimientos, se ha fijado la ley personal del hijo como única conexión a la hora de resolver cuestiones relacionadas con la determinación y el carácter de la filiación por naturaleza -salvo si no pudiera lograrse establecer el referido lugar-, lo que ha aportado cierta luz en torno al debate doctrinal relacionado con esta materia.

26. No menos interesantes resultan las reflexiones de la Sala en torno a interpretación del artículo 767.4 de la Ley de Enjuiciamiento Civil, que en ningún caso puede considerarse que atribuye efectos a pruebas obtenidas de forma irregular, sin garantías en la cadena de custodia del material orgánico recogido y sin contar con el consentimiento del afectado.

27. En definitiva, más allá de la complejidad relacionada con los procedimientos en que se debate en torno a la filiación de un menor, en los que confluyen innegablemente intereses públicos y privados, si además de dicha cuestión concurre elemento de extranjería, nos enfrentaremos a problemas añadidos que vienen relacionados con la determinación, tanto de la ley aplicable, como del órgano jurisdiccional competente para conocer del proceso.

\footnotetext{
${ }^{18}$ Siendo las administraciones públicas las competentes para velar por el derecho de los menores a ser protegidos, para lo que deberán detectar, prevenir e intervenir adecuadamente en atención a las circunstancias concurrentes, adoptando las medidas oportunas de entre las previstas al efecto en la legislación vigente. A. DE PALMA, "El derecho de los menores a la asistencia y protección de las administraciones públicas. Las competencias locales en materia de protección de menores", Cuadernos de Derecho Local, nº. 4, octubre 2004, pp. 103-138.
} 